\title{
Combined Olmesartan, Amlodipine, and Hydrochlorothiazide Therapy in Randomized Patients with Hypertension: A Subgroup Analysis of the TRINITY Study by Age
}

\author{
Andrew J. Lewin · Joseph L. Izzo Jr • \\ Michael Melino • James Lee • Victor Fernandez • \\ Reinilde Heyrman
}

Published online: 3 April 2013

(c) The Author(s) 2013. This article is published with open access at Springerlink.com

\begin{abstract}
Background Hypertension is often inadequately controlled in older people.

Objective This prespecified subgroup analysis assessed the efficacy and safety of an olmesartan medoxomil (OM) $40 \mathrm{mg} /$ amlodipine besylate (AML) $10 \mathrm{mg} /$ hydrochlorothiazide (HCTZ) $25 \mathrm{mg}$ triple-combination treatment compared with the 3 components as dual-combination treatments in participants with hypertension who were $<65$ and $\geq 65$ years of age. Within the $\geq 65$ years of age subgroup, efficacy and safety were also summarized for participants $\geq 75$ years of age.

Study design 12-week, multicenter, double-blind, randomized, parallel-group study.

Setting 317 ambulatory care sites in the US and Puerto Rico.

Participants Individuals $\geq 18$ years of age with mean seated blood pressure $(\mathrm{SeBP}) \geq 140 / 100$ or $\geq 160 /$ $90 \mathrm{mmHg}$ off antihypertensive medication on 2 consecutive clinic visits with no recent history of significant cerebrovascular disease, coronary artery disease, heart
\end{abstract}

A. J. Lewin $(\square)$

National Research Institute, 2010 Wilshire Blvd. Ste. 302,

Los Angeles, CA 90057, USA

e-mail: docl@clinical-studies.com

J. L. Izzo Jr

State University of New York at Buffalo, Buffalo, NY, USA

M. Melino · J. Lee $\cdot$ V. Fernandez

Daiichi Sankyo, Inc, Parsippany, NJ, USA

R. Heyrman

Formerly of Daiichi Sankyo, Inc, Parsippany, NJ, USA failure (New York Heart Association class III or IV), severe renal insufficiency, or uncontrolled diabetes $\left(\mathrm{HbA}_{1 \mathrm{c}}\right.$ $>9 \%)$.

Intervention Participants were randomized, stratified by age, diabetes status, and race to one of four treatment assignments: OM 40/AML 10/HCTZ $25 \mathrm{mg}$, OM 40/AML $10 \mathrm{mg}$, OM 40/HCTZ $25 \mathrm{mg}$, or AML 10/HCTZ $25 \mathrm{mg}$.

Main Outcome Measure Least squares (LS) mean change from baseline in seated diastolic blood pressure (SeDBP) at week 12 (last observation carried forward) in each age subgroup (prespecified analysis).

Results Of the 2492 randomized participants in the study (total cohort), $2021(81.1 \%)$ were $<65$ and 471 (18.9\%) were $\geq 65$ years of age, including 79 (3.2\%) who were $\geq 75$ years of age. OM 40/AML 10/HCTZ $25 \mathrm{mg}$ triplecombination treatment resulted in a significantly greater reduction in LS mean SeDBP at week 12 than dual-combination component treatments in participants in both cohorts: $<65$ years $(21.0$ vs. $14.2-17.2 \mathrm{mmHg}$; $\mathrm{p}<0.0001)$ and $\geq 65$ years (23.7 vs. $17.3-20.0 \mathrm{mmHg} ; \mathrm{p} \leq 0.002$ ). Similarly, triple-combination treatment resulted in a greater reduction in LS mean seated systolic blood pressure (SeSBP) at week 12 than dual-combination component treatments: $<65$ years $(38.2$ vs. $28.3-31.4 \mathrm{mmHg} ; \mathrm{p}<0.0001)$ and $\geq 65$ years ( 39.2 vs. $29.3-31.1 \mathrm{mmHg}$; $<<0.0001$ ). Triplecombination treatment was more effective than dual-combination treatments in enabling participants to reach SeBP goal $(<140 / 90 \mathrm{mmHg}[<130 / 80 \mathrm{mmHg}$ in participants with diabetes, chronic kidney disease, or chronic cardiovascular disease]) in both age subgroups ( $<65$ years: 65 vs. $34-50 \%$, respectively, $\mathrm{p}<0.0001$ and $\geq 65$ years: 63 vs. $32-39 \%$; $\mathrm{p} \leq 0.0004)$. All 4 treatments were safe and well tolerated with low discontinuation rates in both age subgroups. There were no clinically relevant differences in the incidence of treatment-emergent adverse events between participants 
$<65$ and $\geq 65$ years of age receiving triple-combination treatment.

Conclusion Triple-combination treatment with $\mathrm{OM}$ 40/AML 10/HCTZ $25 \mathrm{mg}$ was well tolerated and more effective in lowering BP than the component dual-combination treatments in elderly and non-elderly subgroups.

\section{Introduction}

The prevalence of hypertension rises with age [1-4]. In the US, hypertension occurs in $70.8 \%$ of women and $63.9 \%$ of men 65-74 years of age and $80.1 \%$ of women and $72.1 \%$ of men $\geq 75$ years of age, largely due to increased systolic blood pressure (SBP) [1]. Individuals over 60 years of age are also the most rapidly growing segment of the US population. By 2025, the worldwide prevalence of hypertension will reach $50.3 \%$ in women and $46.0 \%$ in men 60-69 years of age and $66.8 \%$ in women and $57.1 \%$ in men $\geq 70$ years of age [5].

Adequately treating hypertension is important since cardiovascular disease risk is doubled with each 7 years of advancing age, $20-\mathrm{mmHg}$ increment in SBP, or 10-mmHg increment in diastolic BP (DBP) [6]. National Health and Nutrition Examination Survey (NHANES) data indicate that only $53 \%$ of individuals $\geq 60$ years of age have adequate BP control [1]. In order to achieve adequate BP reduction, many elderly individuals require more than one drug [7]. If multiple-pill therapies adversely affect therapeutic adherence in this population $[8,9]$, many elderly patients with hypertension may benefit from single-pill, multiple-combination therapy $[5,10,11]$.

In the Triple Therapy with Olmesartan Medoxomil, Amlodipine, and Hydrochlorothiazide in Hypertensive Patients Study (TRINITY; ClinicalTrials.gov Identifier: NCT00649389), the triple-combination treatment of olmesartan medoxomil (OM) $40 \mathrm{mg}$, amlodipine besylate (AML) $10 \mathrm{mg}$, and hydrochlorothiazide (HCTZ) $25 \mathrm{mg}$ reduced both seated DBP (SeDBP) and seated SBP (SeS$\mathrm{BP})$ to a greater degree than the 3 dual-combination treatments, enabling a greater proportion of study participants to reach BP goal $(<140 / 90 \mathrm{mmHg}[<130 / 80 \mathrm{mmHg}$ in participants with diabetes, chronic kidney disease, or chronic cardiovascular disease]) [12]. The objective of the current prespecified TRINITY subgroup analysis was to evaluate the efficacy and safety of the OM 40/AML 10/HCTZ $25 \mathrm{mg}$ triple-combination treatment compared with the 3 component dual-combination treatments in participants with hypertension who were $<65$ and $\geq 65$ years of age. Within the $\geq 65$ years of age subgroup, efficacy and safety were also summarized for participants $\geq 75$ years of age.

\section{Methods}

\subsection{Study Population}

The detailed TRINITY study design and results of the 12-week randomized phase for the total population have been previously reported [12]. Briefly, the TRINITY study was a multicenter, double-blind, randomized, parallelgroup trial conducted at 317 clinical sites in the US and Puerto Rico. Individuals eligible for randomization were $\geq 18$ years of age with mean seated BP (SeBP) $\geq 140 / 100$ or $\geq 160 / 90 \mathrm{mmHg}$ on 2 consecutive visits off antihypertensive medication. Persons with a recent history ( $\leq 6$ months) or presence of significant cardiovascular or cerebrovascular disease, coronary artery disease, New York Heart Association class III or IV congestive heart failure, severe renal insufficiency (defined as creatinine clearance $<30 \mathrm{~mL} / \mathrm{min}$ ), or uncontrolled diabetes (defined as hemoglobin A1c $>9 \%$ ) were excluded. Individuals with type 1 or type 2 diabetes whose diabetes was controlled for $\geq 30$ days by a stable regimen of diet, insulin, or oral hypoglycemic agents and persons with chronic kidney disease (creatinine clearance $\geq 30$ and $\leq 60 \mathrm{~mL} / \mathrm{min}$ ) were eligible to participate. The study was conducted in accordance with the institutional review board committee regulations and the Declaration of Helsinki, and written informed consent was obtained from each individual before participation in any study procedures.

\subsection{Study Design and Procedures}

The study included a 3-week washout period (for participants receiving antihypertensive treatment at screening) followed by a 12 -week double-blind treatment period. On day 1, eligible study participants were randomized using an interactive voice response system to a treatment sequence that led to their final treatment assignment (OM 40/AML 10/HCTZ $25 \mathrm{mg}$ [given as OM 40/HCTZ $25 \mathrm{mg}$ fixed-dose combination plus AML $10 \mathrm{mg}$ given separately], OM 40/AML $10 \mathrm{mg}$ [fixed-dose combination], OM 40/HCTZ $25 \mathrm{mg}$ [fixed-dose combination], or AML 10/HCTZ $25 \mathrm{mg}$ [given separately]). All participants received dual-combination treatment for 2 weeks, except for a subset of 36 study participants who had not been on antihypertensive medications for at least 3 weeks and who received placebo for 2 weeks (in order to assess the study for nontreatment-associated BP effects). All participants assigned to dual-combination treatment remained on their assigned treatment until week 4. All participants on placebo at week 2 were switched to 1 of the 3 dual-combination treatments from week 2 to week 4 . At week 4, participants were either maintained on dual-combination treatment to week 12 or switched to triple-combination treatment with $\mathrm{OM}$ 
40/AML 10/HCTZ $25 \mathrm{mg}$ until week 12. Study participants were instructed to take all study medication at the same time $( \pm 2 \mathrm{~h})$ each day and investigators and study participants remained blinded as to which medication was being administered at any given time [12].

BP was measured at all study visits during the doubleblind treatment period, including day 1 and weeks 2, 4, 6, 8,10 , and 12. BP was measured at all sites using an automated BP monitor (OMRON HEM-705CP, Omron Healthcare, Inc., Bannockburn, Illinois) that produced a printout of each BP assessment with the use of a cuff of appropriate size. Measurements were taken with the patient in a seated position after a 5-min rest. Three BP measurements were obtained at 1-min intervals during each visit [12].

\subsection{Efficacy Assessments}

The primary efficacy variable was the least squares (LS) mean change from baseline to week 12 in SeDBP in each age subgroup. Secondary efficacy variables included the LS mean change from baseline to week 12 in SeSBP, proportion of study participants reaching SeBP goal $(<140 /$ $90 \mathrm{mmHg}[<130 / 80 \mathrm{mmHg}$ in study participants with diabetes, chronic kidney disease, or chronic cardiovascular disease]) at week 12 , proportion of study participants achieving SeBP target $(<140 / 90 \mathrm{mmHg})$ at week 12 (subgroup post hoc analysis), and the mean change in SeBP from baseline to week 12 in study participants with severe hypertension (SeSBP $\geq 180 \mathrm{mmHg}$ or SeDBP $\geq 110 \mathrm{mmHg}$ ) at baseline (subgroup post hoc analysis).

\subsection{Safety Assessments}

Safety was assessed at all study visits. Safety assessments included physical examinations (including vital signs), 12-lead electrocardiograms, clinical laboratory testing, and adverse events.

\subsection{Statistical Analysis}

The primary efficacy analysis included all study participants who had baseline assessment of SeDBP, received at least 1 dose of study medication, and had at least 1 postdose assessment of SeDBP (efficacy cohort). The primary safety population for the assessment of adverse events was defined as study participants who took at least 1 dose of study medication at or beyond the week 4 visit (first-week participants randomized to triple-combination treatment actually received this treatment [safety cohort]).

The efficacy of triple- versus each dual-combination treatment in reducing SeBP within age subgroups was assessed using two-sided p-values derived from an analysis of covariance (ANCOVA) model that had baseline BP as a covariate and final randomized treatment, subgroup, and final randomized treatment by subgroup interaction as fixed effects. The LS mean difference and standard error (SE) derived from the ANCOVA model were used to calculate the baseline change in SeBP at week 12. The proportion of study participants reaching BP goal and target by treatment within age subgroups was summarized and analyzed using the chi-square test. The efficacy of triple-combination treatment versus each dual-combination treatment in reaching BP goal and target with age subgroups was assessed using Fisher's exact test at a 0.05 significance level. To account for potential missing data during the double-blind treatment period, each of these analyses used a last observation carried forward (LOCF) approach.

The TRINITY study was powered to assess treatment efficacy in the overall study population. Sample size was determined assuming $97 \%$ power for each of the 3 pairwise comparisons of interest so that a desired overall power of $90 \%$ could be achieved. The study was not powered to assess efficacy between age subgroups. In addition, there was a small number of study participants in the $\geq 75$ years of age subgroup (79 [3.2\%]) who were included in the $\geq 65$ years of age subgroup. In the $\geq 75$ years of age subgroup, there were only $25,19,17$, and 18 participants receiving OM 40/AML $10 \mathrm{mg}$, OM 40/HCTZ $25 \mathrm{mg}$, AML 10/HCTZ $25 \mathrm{mg}$, and OM 40/AML 10/HCTZ $25 \mathrm{mg}$, respectively. For these reasons, the evaluation of the $\geq 75$ years of age subgroup was for observational purposes, and summary data without statistical comparison are presented.

\section{Results}

\subsection{Study Population}

Of the 2492 study participants randomized in the TRINITY study (total cohort), 2021 (81.1\%) were $<65$ years of age and $471(18.9 \%)$ were $\geq 65$ years of age, including $79(3.2 \%)$ who were $\geq 75$ years of age. Mean ages in the $\geq 65$ and $<65$ years of age subgroups were 70.5 (minimum: 65, maximum: 92 years) and 51.5 (minimum: 20, maximum: 64 years), respectively. Both subgroups had a similar prevalence of male participants ( $\geq 65$ years of age: $51.2 \%$; $<65$ years of age: $53.3 \%$ ). However, study participants $\geq 65$ years of age had a greater prevalence of diabetes than study participants $<65$ years of age $(21.4$ vs. $14.2 \%$, respectively), a lower mean body mass index (31.3 vs. $33.5 \mathrm{~kg} / \mathrm{m}^{2}$ ), a longer mean duration of hypertension (14.4 vs. 8.9 years), a greater mean SeSBP (173.5 vs. $167.3 \mathrm{mmHg}$ ), a lower mean SeDBP (96.6 vs. $102.0 \mathrm{mmHg}$ ), and a greater prevalence of severe hypertension (30.6 vs. $24.1 \%$ ) at 
baseline. Mean SeBP at baseline was similar in the $\geq 75$ and $\geq 65$ years of age subgroups (174.5/94.7 and 173.5/ $96.6 \mathrm{mmHg}$, respectively) and the prevalence of severe hypertension was $34.2 \%$ in the $\geq 75$ years of age subgroup and $30.6 \%$ in the $\geq 65$ years of age subgroup.

Table 1 summarizes demographic and clinical characteristics at baseline by randomized treatment assignment for each age subgroup.

\subsection{Efficacy}

Regardless of age, all 4 treatments resulted in significant reductions from baseline in SeDBP and SeSBP at week 12 (LOCF; Fig. 1). Triple-combination treatment with OM 40/AML 10/HCTZ $25 \mathrm{mg}$ resulted in significantly greater SeBP reductions than any of the dual-combination treatments in both the $<65$ and $\geq 65$ years of age subgroups. The efficacy of all 4 treatments in the $\geq 75$ years of age subgroup appeared comparable to the efficacy in the $\geq 65$ years of age subgroup as a whole. Overall, the LS mean reduction in SeBP at week 12 with triple-combination treatment was approximately $38 / 21 \mathrm{mmHg}$ in study participants $<65$ years of age ( $p<0.0001$ vs. each dualcombination treatment), approximately $39 / 24 \mathrm{mmHg}$ in study participants $\geq 65$ years of age ( $p \leq 0.002$ vs. each dual-combination treatment), and approximately $40 / 26 \mathrm{mmHg}$ in study participants $\geq 75$ years of age. In each age subgroup, the efficacy of triple- versus dualcombination treatment was typically present within 2 weeks (week 6) of initiating OM 40/AML 10/HCTZ $25 \mathrm{mg}$ (week 4), and was maintained throughout the remainder of the double-blind treatment period (Fig. 2).

As a result, triple-combination treatment was significantly more effective than the component dual-combination treatments in enabling study participants $<65$ and $\geq 65$ years of age to reach BP goal $(<140 / 90$ or $<130$ / $80 \mathrm{mmHg}$ in study participants with diabetes, chronic kidney disease, or chronic cardiovascular disease) at week 12 (LOCF), and numerically similar findings were seen in the $\geq 75$ years of age subgroup (Fig. 3). Overall, approximately 65,63 , and $56 \%$ of study participants randomized to triplecombination treatment in the $<65, \geq 65$, and $\geq 75$ years of age subgroups, respectively, reached BP goal at week 12 (Fig. 3). Likewise, triple-combination treatment was more effective than the component dual-combination treatments in achieving the BP target of $<140 / 90 \mathrm{mmHg}$ at week 12 (LOCF) in all 3 age subgroups (Fig. 4; post hoc analysis).

The efficacy of triple- versus dual-combination treatment appeared to be maintained across age subgroups in the subset of study participants with severe hypertension (SeSBP $\geq 180 \mathrm{mmHg}$ or SeDBP $\geq 110 \mathrm{mmHg}$ ). In this subset, mean SeBP at week 12 (LOCF) in study participants randomized to triple-combination treatment in the
$<65, \geq 65$, and $\geq 75$ years of age subgroups was reduced approximately $47 / 24,50 / 23$, and $47 / 21 \mathrm{mmHg}$, respectively, compared with mean reductions of 36-38/18-21, $38-41 / 16-18$, and $36-43 / 17-22 \mathrm{mmHg}$ in study participants randomized to dual-combination treatments in the same age subgroups (Fig. 5; post hoc analysis).

An ad hoc analysis was performed to determine if there was a trend toward BP reduction using age as a continuous covariate. A linear regression analysis for change in $\mathrm{BP}$ from baseline to the end of the 12-week treatment period demonstrated statistical significance $(p<0.05)$ for triplecombination therapy for both SeDBP and SeSBP. The only other combination therapy which demonstrated a similar pharmacodynamic effect for BP reduction was the dual combination of AML 10/HCTZ $25 \mathrm{mg}$.

\subsection{Safety}

Triple- and dual-combination treatments were safe and well tolerated across age subgroups and no new safety concerns were identified that were not known to occur with the individual component therapies (Table 2). Overall, $1034(55.6 \%), 253(57.1 \%)$, and $36(50.7 \%)$ study participants in the $<65, \geq 65$, and $\geq 75$ years of age subgroups, respectively, had a treatment-emergent adverse event (TEAE) and $474(25.5 \%), 111(25.1 \%)$, and $17(23.9 \%)$ study participants in these same age subgroups had a drugrelated TEAE. Most of these adverse events were considered mild or moderate in severity across both treatment and age subgroups. Serious adverse events occurred in 22 $(1.2 \%), 13(2.9 \%)$, and $1(1.4 \%)$ study participant(s) in the $<65, \geq 65$, and $\geq 75$ years of age subgroups, respectively, and $40(2.2 \%), 13(2.9 \%)$, and $3(4.2 \%)$ study participants in these same age subgroups discontinued their study medication due to an adverse event.

TEAEs occurring in $\geq 3 \%$ of study participants on any treatment regimen in the $<65$ or $\geq 65$ years of age subgroups are listed in Table 2. The most common TEAEs ( $\geq 5 \%$ in any treatment group) were dizziness $(7.2 \%$ ), headache $(6.4 \%)$, peripheral edema $(5.5 \%)$, and fatigue $(5.5 \%)$ in the $<65$ years of age subgroup; peripheral edema $(7.9 \%)$, headache $(7.0 \%)$, dizziness $(6.3 \%)$, and fatigue $(5.2 \%)$ in the $\geq 65$ years of age subgroup; and peripheral edema $(8.5 \%)$, joint swelling $(7.0 \%)$, upper respiratory tract infection (5.6\%), and dizziness (5.6\%) in the $\geq 75$ years of age subgroup. However, in the $\geq 75$ years of age subgroup, no more than 3 participants experienced 1 of these TEAEs on any treatment regimen. In particular, the incidence of hypotension $(<65$ years of age: $0.4 \%$; $\geq 65$ years of age: $0.7 \%$ ), vertigo $(<65$ years of age: $0.3 \%$; $\geq 65$ years of age: $0.5 \%$ ), and falls ( $<65$ years of age: $0.3 \%$; $\geq 65$ years of age: $0.7 \%$ ) were low across age subgroups for all treatment regimens. Orthostatic 


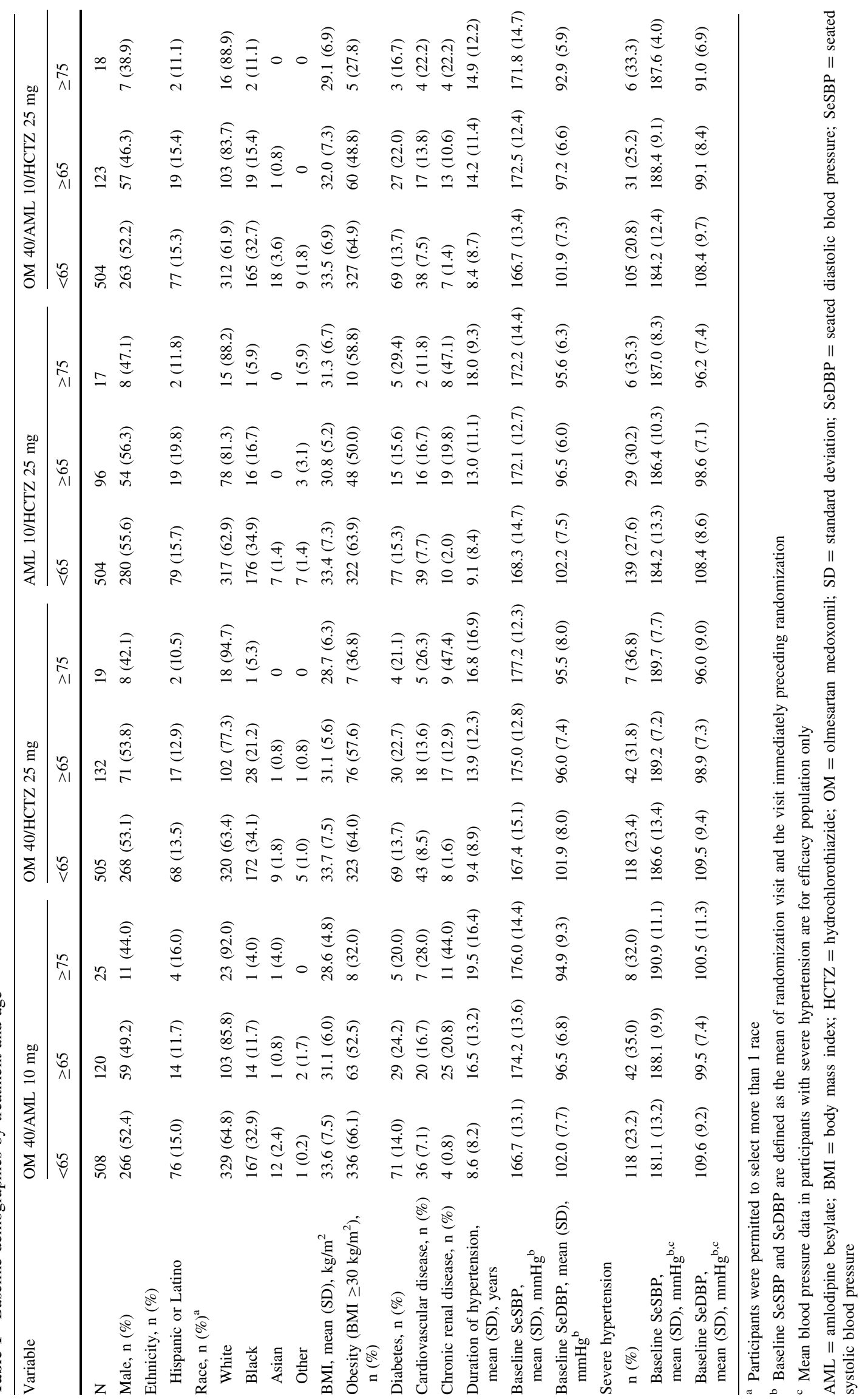




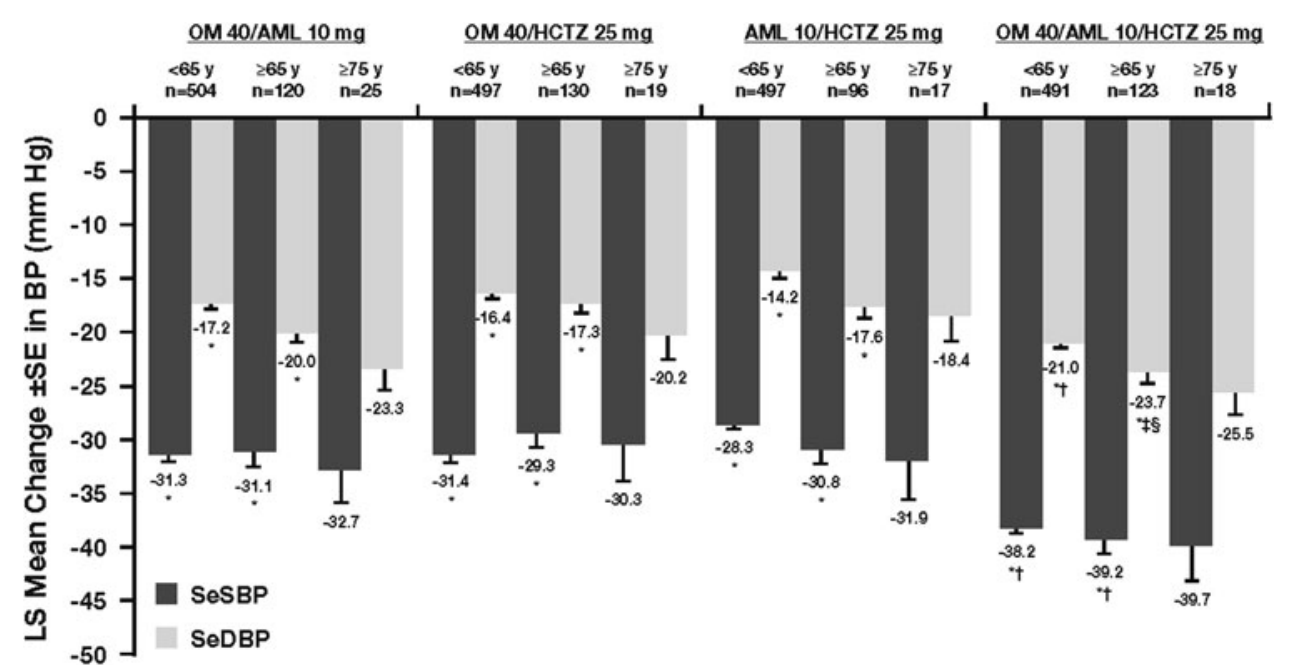

Fig. 1 Least squares (LS) mean reductions in seated diastolic blood pressure (SeDBP; primary efficacy variable) and seated systolic blood pressure (SeSBP) at week 12 (last observation carried forward) by treatment and age. Error bars depict standard error (SE) of BP change. ${ }^{*} \mathrm{p}<0.0001$ vs baseline; ${ }^{\dagger} \mathrm{p}<0.0001$ vs each dual-

hypotension was experienced in $0.2 \%$ of participants who were $<65$ years of age and was not reported in any participant $\geq 65$ years of age in any treatment group.

There were no clinically relevant differences in the incidence of TEAEs between study participants $<65$ and $\geq 65$ years receiving triple-combination treatment. Although the number of participants in the $\geq 75$ years of age subgroup who were receiving triple-combination treatment was small $(n=16)$, there did not appear to be any clinically relevant differences in the incidence of TEAEs between this age subgroup (overall incidence: $56 \%$ ) and the other age subgroups.

\section{Discussion}

This prespecified subgroup analysis of the TRINITY study demonstrated the efficacy and safety of triple-combination OM 40/AML 10/HCTZ $25 \mathrm{mg}$ treatment in elderly participants with hypertension. Compared with the component dual-combination treatments, triple-combination treatment with OM/AML/HCTZ resulted in greater mean reductions in BP and enabled a larger proportion of study participants to achieve BP goals in all 3 age subgroups. All treatments were well tolerated. The largest BP reductions observed in this evaluation occurred in the very elderly ( $\geq 75$ years of age) in participants receiving OM 40/AML 10/HCTZ $25 \mathrm{mg}(\mathrm{n}=18)$. This subgroup was a subset of the $\geq 65$ years of age subgroup, which may have contributed to the demonstrated efficacy. The $\geq 75$ years of age subgroup also had the highest absolute rates of cardiovascular disease in patients receiving OM 40/AML 10/HCTZ $25 \mathrm{mg}$. combination treatment within age subgroup; ${ }^{\ddagger}=0.002$ vs $\mathrm{OM}$ 40/AML $10 \mathrm{mg}$ treatment within age subgroup; ${ }^{8} \mathrm{p}<0.0001$ vs OM 40/HCTZ $25 \mathrm{mg}$ and AML 10/HCTZ $25 \mathrm{mg}$ treatments within age subgroup. $\mathrm{AML}=$ amlodipine besylate; $\mathrm{HCTZ}=$ hydrochlorothiazide; $\mathrm{OM}=$ olmesartan medoxomil

The potential impact of these observations is substantial because epidemiologic data suggest that a reduction in SBP of $20 \mathrm{mmHg}$ or $\mathrm{DBP}$ of $10 \mathrm{mmHg}$ has the potential to reduce adverse events by as much as $50 \%$ [6]. The favorable benefits observed in outcome trials have resulted in current guidance that hypertension should be treated vigorously in all patients, regardless of age [2]. In general, those with the best BP control also have the best outcomes. Thus, the Seventh Report of the Joint National Committee on Prevention, Detection, Evaluation, and Treatment of High Blood Pressure (JNC 7) recommends a BP goal of $<140 / 90 \mathrm{mmHg}(<130 / 80 \mathrm{mmHg}$ in patients with diabetes or chronic kidney disease), regardless of age [2].

Numerous clinical trials have established the benefits of hypertension treatment in these patients [13-24]. In the 1980s, the European Working Party on High Blood Pressure in the Elderly (EWPHE) demonstrated in a randomized, double-blind, placebo-controlled study that treating hypertension in participants $\geq 60$ years of age significantly reduced cardiac $(38 \%, \mathrm{p}=0.036)$ and cardiovascular (27\%, p =0.037) mortality [13]. More recently, the Hypertension in the Very Elderly Trial (HYVET) demonstrated that treating hypertension in participants $\geq 80$ years of age to SBP values $<150 \mathrm{mmHg}$ reduced heart failure by $64 \%(\mathrm{p}<0.001)$, stroke mortality by $39 \%(\mathrm{p}=0.046)$, cardiovascular mortality by $23 \%(\mathrm{p}=0.06)$, and all-cause mortality by $21 \%(\mathrm{p}=0.02)$ [20]. Consistent with these findings, a meta-analysis of data from 15 trials found that treating hypertension in participants $\geq 60$ years of age significantly reduced all-cause mortality (risk ratio [RR]: 0.90; $95 \%$ confidence interval [CI]: 0.84-0.97), cardiovascular mortality (RR: 0.77; $95 \%$ CI: 0.68-0.86), 
Fig. 2 Mean seated systolic blood pressure (SeSBP; a) and seated diastolic blood pressure (SeDBP; b) from baseline to week 12 by treatment and age. Week 4 is the first week of triple-combination treatment. Prior to week 4 , study participants randomized to triple-combination treatment received 1 of 3 dualcombination regimens. $\mathrm{AML}=$ amlodipine besylate; $\mathrm{HCTZ}=$ hydrochlorothiazide; $\mathrm{OM}=$ olmesartan medoxomil
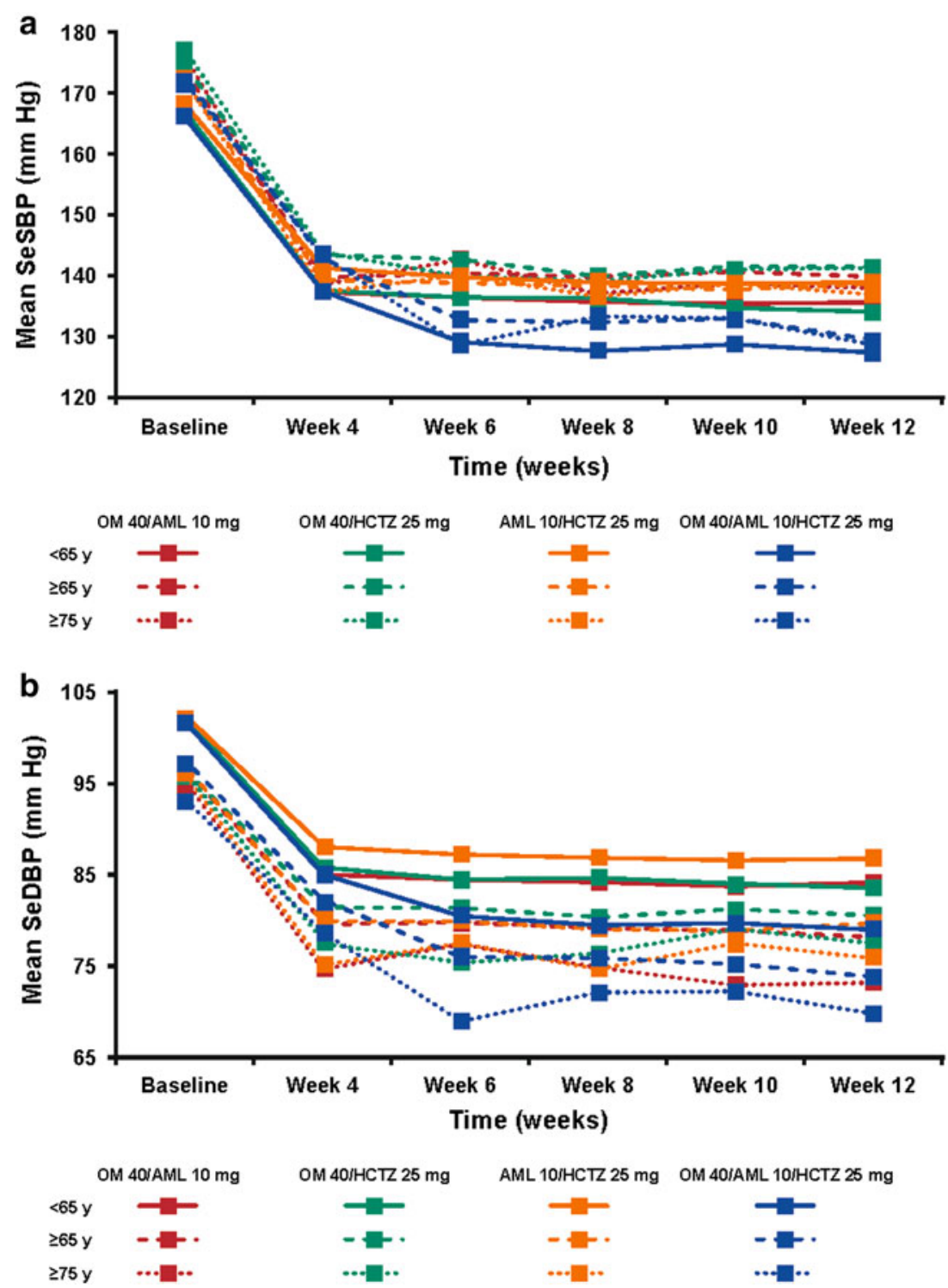

coronary heart disease mortality (RR: $0.77 ; 95 \%$ CI: 0.65-0.90), and cerebrovascular mortality (RR: 0.66; $95 \%$ CI: 0.53-0.82) [21].

Combination therapy is an attractive approach [2]. Successfully applying advanced BP goals in elderly patients remains challenging [1,2]: only about $20 \%$ of these patients achieve the recommended BP targets [2]. In hypertension, the etiology of BP elevation is usually multifactorial, making it unlikely that BP control can be achieved by modulating a single mechanism [4, 25]. The JNC 7 guidelines state that most patients with hypertension require 2 or more antihypertensive medications to achieve BP goal but overall, at least $75 \%$ of patients with hypertension will require at least 2 agents and at least $25 \%$ need at least 3 agents to achieve BP goal (these percentages represent data from a controlled environment of a clinical trial and findings cannot be extrapolated to the general population) [2, 7, 25-29]. In the Study on Cognition and Prognosis in the Elderly (SCOPE), $49 \%$ of participants randomized to active treatment were receiving at least 3 antihypertensive agents by study end [7]. Similarly, in the Anglo-Scandinavian Cardiac Outcomes Trial-Blood Pressure Lowering Arm (ASCOT-BPLA), $78 \%$ of participants with hypertension and $\geq 3$ other cardiovascular risk factors were receiving at least 2 and $61 \%$ at least 3 antihypertensive agents by study end; addition of a third antihypertensive agent resulted in approximately $30 \%$ of participants with previously uncontrolled hypertension achieving BP goal $(<140 / 90 \mathrm{mmHg}[<130 / 80 \mathrm{mmHg}$ in participants with diabetes]) [30,31]. Thus, the American College of Cardiology Foundation (ACCF)/American Heart Association (AHA) 2011 Expert Consensus Document on Hypertension in the Elderly recommends adding a third drug from another class if the antihypertensive 
Fig. 3 Proportion of study participants reaching blood pressure (BP) goal $(<140 /$ $90 \mathrm{mmHg}[<130 / 80 \mathrm{mmHg}$ in study participants with diabetes, chronic kidney disease, or chronic cardiovascular disease]) at week 12 (last observation carried forward) by treatment and age. $* \mathrm{p}<0.0001$, ${ }^{\dagger} \mathrm{p} \leq 0.0004$ vs each dual-combination treatment within age subgroup. $\mathrm{AML}=$ amlodipine besylate; $\mathrm{HCTZ}=$ hydrochlorothiazide; $\mathrm{OM}=$ olmesartan medoxomil

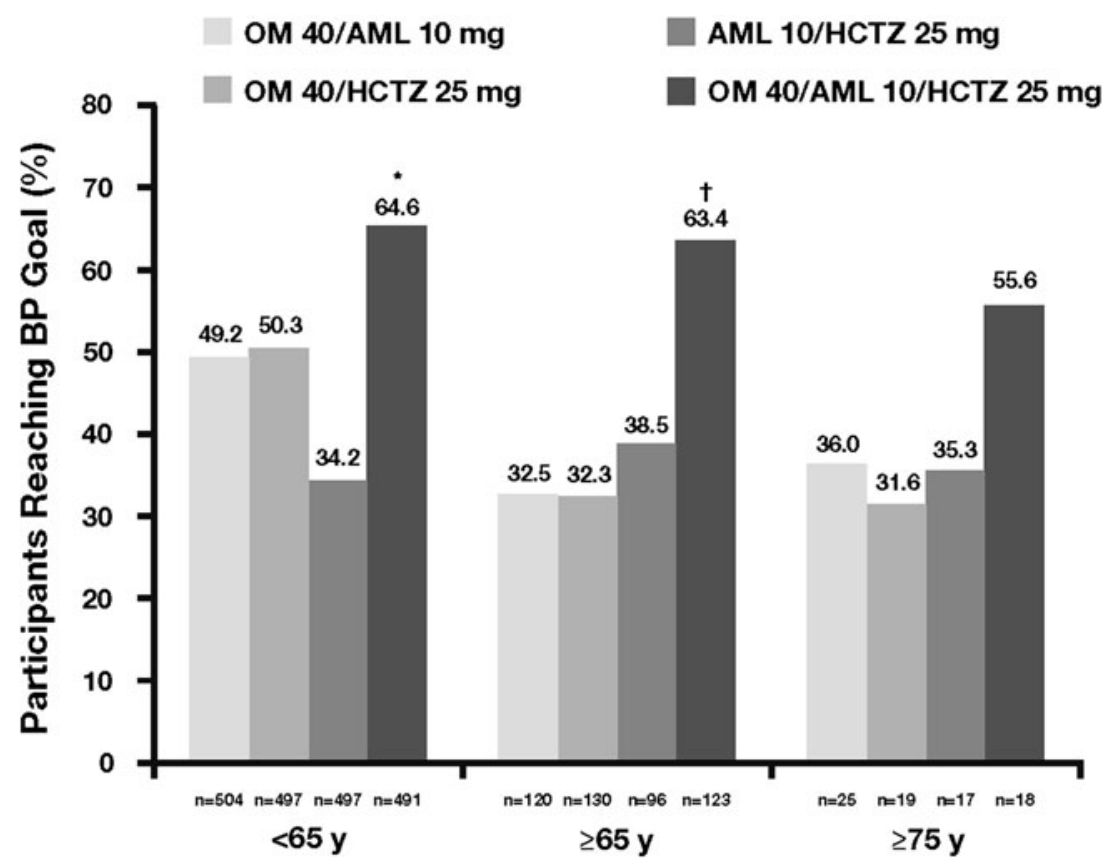

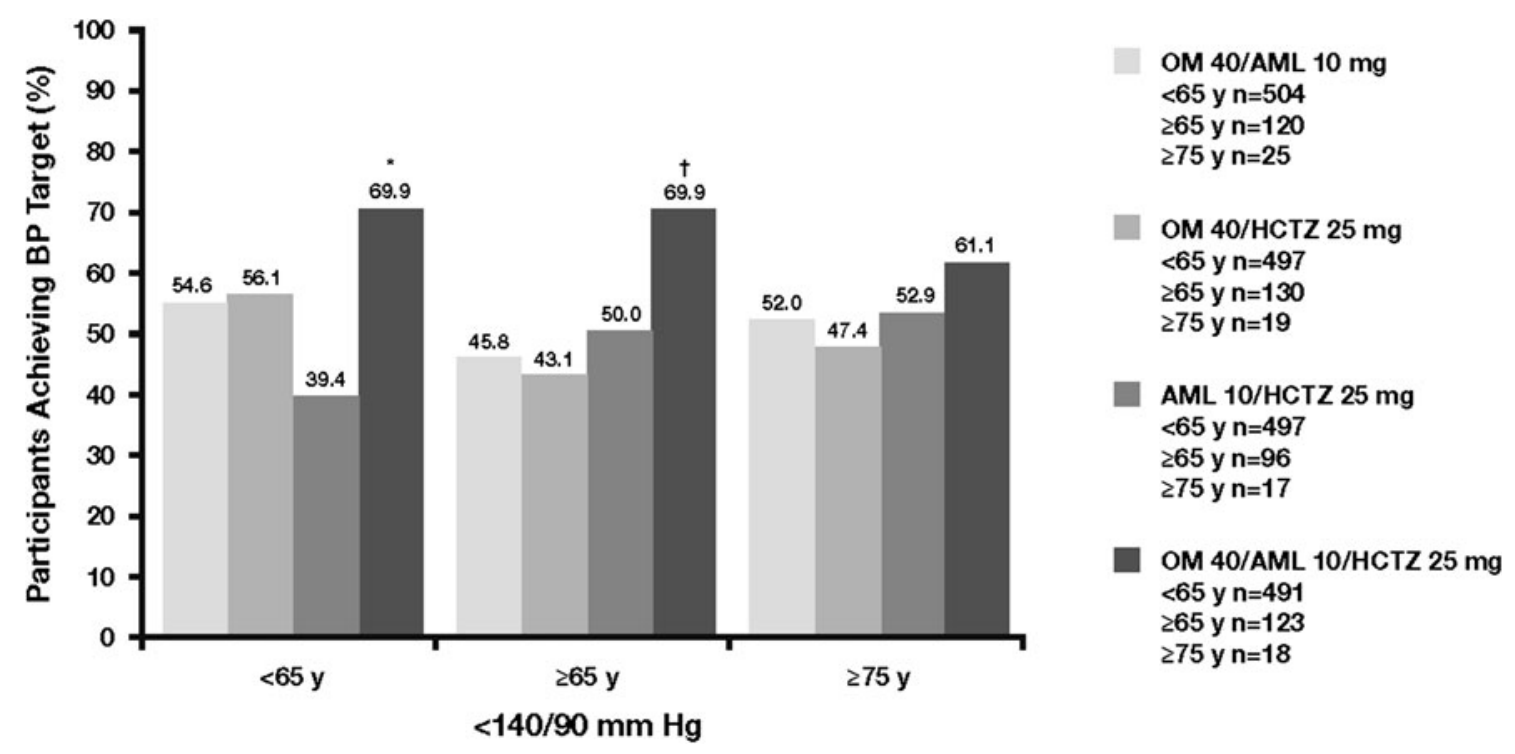

Fig. 4 Proportion of study participants achieving blood pressure (BP) target $(<140 / 90 \mathrm{mmHg})$ at week 12 (last observation carried forward) by treatment and age (post hoc analysis). $* \mathrm{p}<0.0001$,

response is inadequate compared to full doses of 2 drugs from different classes [4].

BP control in the elderly is also complicated by adverse events, such as hypotension, and drug interactions [4]. Elderly patients are also more likely to have end organ damage that may influence drug selection and response to therapy $[2,4]$. In addition, pathophysiologic, lifestyle, and treatment-related factors in these patients may adversely affect compliance with any antihypertensive therapeutic regimen [4].
${ }^{\dagger} \mathrm{p}<0.005$ vs each dual-combination treatment within age subgroup. $\mathrm{AML}=$ amlodipine besylate $\mathrm{HCTZ}=$ hydrochlorothiazide; $\mathrm{OM}=$ olmesartan medoxomil

In the present study, triple-combination treatment was well tolerated in participants $<65$ and $\geq 65$ years of age, with a similar prevalence of TEAEs (57.7 and $61.0 \%$ ), drug-related TEAEs (27.6 and $30.5 \%$ ), and study drug discontinuations due to a TEAE (3.9 and $4.2 \%$ ). The incidence of hypotension was similar across age groups ( $<65$ years of age: $0.4 \%$; $\geq 65$ years of age: $0.7 \%$ ); however, more participants $\geq 75$ years of age $(4.2 \%)$ discontinued their study medication due to an adverse event compared with participants $<65$ years of age $(2.2 \%)$ and 
Fig. 5 Mean reductions in blood pressure (BP) at week 12 (last observation carried forward) by treatment and age in study participants with severe hypertension at baseline (post hoc analysis). Severe hypertension was defined as seated systolic BP (SeSBP) $\geq 180 \mathrm{mmHg}$ or seated diastolic $\mathrm{BP}(\mathrm{SeDBP}) \geq 110 \mathrm{mmHg}$. $\mathrm{AML}=$ amlodipine besylate; $\mathrm{HCTZ}=$ hydrochlorothiazide; $\mathrm{OM}=$ olmesartan medoxomil; $\mathrm{SD}=$ standard deviation

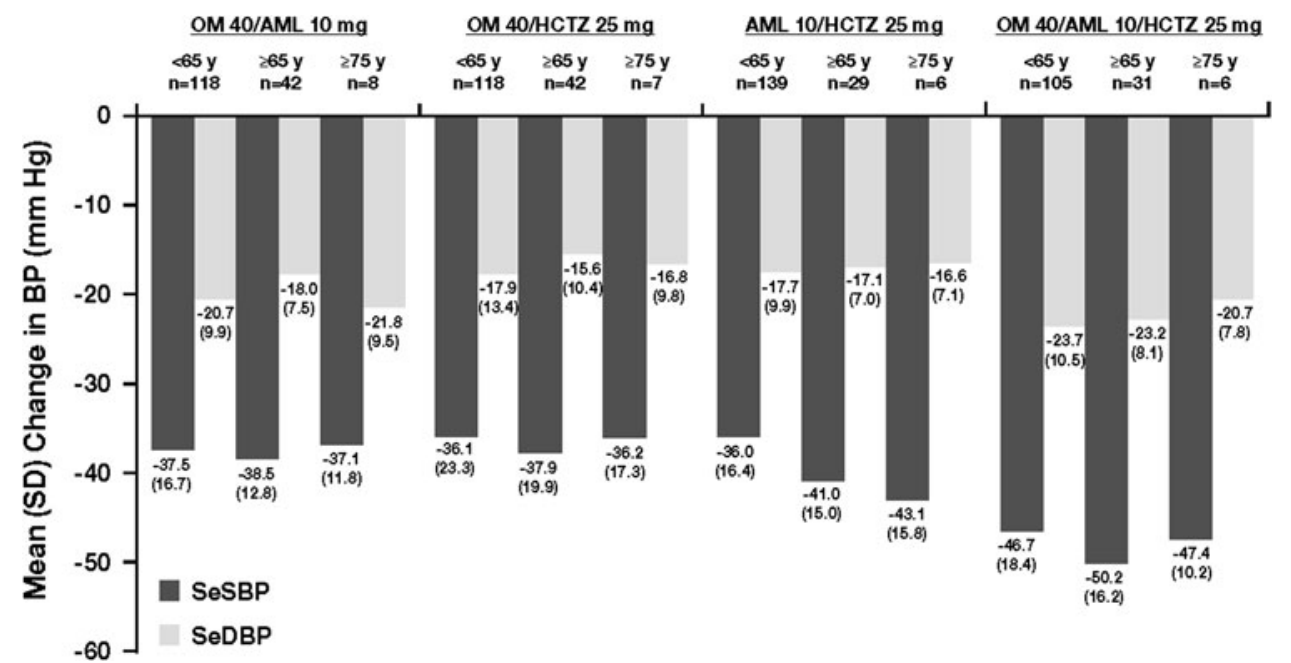

$\geq 65$ years of age $(2.9 \%)$. OM either as monotherapy or in combination with HCTZ and/or AML is an effective and safe treatment for hypertension in a broad range of patients, including the elderly [32-36]. In one study, 52-67\% of study participants $\geq 65$ years of age receiving OM/HCTZ combination therapy achieved the SeBP goal of $<140 /$ $90 \mathrm{mmHg}$, while in another study, $61 \%$ of participants $\geq 65$ years of age receiving OM/AML combination therapy, with or without HCTZ, achieved the SeBP goal of $<140 / 90 \mathrm{mmHg}(<130 / 80 \mathrm{mmHg}$ in participants with diabetes) [32, 34]. In patients with diabetes, chronic kidney disease, or chronic cardiovascular disease, short-term (12 weeks) and long-term treatment with OM 40/AML 10/HCTZ $25 \mathrm{mg}$ was well tolerated, lowered BP more effectively, and enabled more participants to reach BP goal than the corresponding dual-combination therapies [37]. Furthermore, in another multinational, phase 3 study, adding HCTZ to a range of OM/AML dose combinations was well tolerated and improved BP control by significantly lowering BP in patients with moderate-to-severe hypertension [38].

A critical factor in achieving benefit is adherence to therapy, which has been shown to correlate inversely with the number of pills in a therapeutic regimen $[8,9,39]$. Nonadherence is a major contributing factor to inadequate BP control [40-42] and can be particularly problematic in elderly individuals taking polypharmacotherapy (often with 6 or more medications) for multiple comorbidities [4]. The ACC/AHA 2011 Expert Consensus states that potential benefits of single-pill combination therapy include increased efficacy, reduced adverse events, and additive target organ protection [4]. Furthermore, by decreasing the number of copayments required, this therapy could reduce out-of-pocket costs, an important consideration in the elderly due to lower incomes [4, 43]. Thus, single-pill combination therapy provides a convenient and effective option for many patients that may increase adherence and persistence [44-49].

Certain limitations exist in this study. While the evaluation of the elderly ( $\geq 75$ years of age and $\geq 65$ years of age) and non-elderly subgroups ( $<65$ years of age) was pre-defined, statistical analyses between these subgroups was not completed because of the unequal participant numbers in the subgroups. Achieved SeBP reductions were comparable with treatment cohorts and the age subgroups and did not warrant further analyses between subgroups. Participants with various illnesses, including active heart disease and poorly controlled diabetes (i.e., $\mathrm{HbA}_{1 \mathrm{c}}>9 \%$ ), were excluded from participation; therefore, caution must be exercised regarding generalizability of these data to the overall population. In addition, the TRINITY study evaluated only a single dose for each agent used and therefore does not provide information on the efficacy or safety of these regimens using different dosing schemes. Also, in clinical practice, patients are likely to be titrated from no drugs to 1 drug, 2 drugs, and then a regimen with 3 drugs. While the TRINITY 12-week study is not designed in this way, it is reasonable to assume that if patients were titrated in the study as they are in clinical practice, the total BP reduction would be similar.

\section{Conclusions}

This prespecified subgroup analysis of the TRINITY study demonstrated that OM 40/AML 10/HCTZ $25 \mathrm{mg}$ triplecombination treatment was both safe and effective in study participants with hypertension, regardless of age. Triplecombination treatment resulted in greater reductions in SeSBP and SeDBP and, as a result, was more effective in enabling study participants to reach BP goal compared with the component dual-combination treatments in all age 
Table 2 Study participants with TEAEs by treatment and age

\begin{tabular}{|c|c|c|c|c|c|c|c|c|}
\hline \multirow[t]{2}{*}{ TEAEs, $\mathrm{n}(\%)^{\mathrm{b}}$} & \multicolumn{2}{|c|}{ OM 40/AML $10 \mathrm{mg}$} & \multicolumn{2}{|c|}{ OM 40/HCTZ $25 \mathrm{mg}$} & \multicolumn{2}{|c|}{ AML 10/HCTZ $25 \mathrm{mg}$} & \multicolumn{2}{|c|}{ OM 40/AML 10/HCTZ $25 \mathrm{mg}$} \\
\hline & $\begin{array}{l}<65 \\
(\mathrm{n}=483)\end{array}$ & $\begin{array}{l}\geq 65 \\
(\mathrm{n}=113)\end{array}$ & $\begin{array}{l}<65 \\
(\mathrm{n}=457)\end{array}$ & $\begin{array}{l}\geq 65 \\
(\mathrm{n}=123)\end{array}$ & $\begin{array}{l}<65 \\
(\mathrm{n}=463)\end{array}$ & $\begin{array}{l}\geq 65 \\
(\mathrm{n}=89)\end{array}$ & $\begin{array}{l}<65 \\
(\mathrm{n}=456)\end{array}$ & $\begin{array}{l}\geq 65 \\
(\mathrm{n}=118)\end{array}$ \\
\hline ALL TEAEs & $250(51.8)$ & $58(51.3)$ & $254(55.6)$ & $65(52.8)$ & $267(57.7)$ & $58(65.2)$ & $263(57.7)$ & $72(61.0)$ \\
\hline Drug-related TEAEs ${ }^{\mathrm{c}}$ & $116(24.0)$ & $22(19.5)$ & $97(21.2)$ & $24(19.5)$ & $135(29.2)$ & $29(32.6)$ & $126(27.6)$ & $36(30.5)$ \\
\hline \multicolumn{9}{|l|}{ Discontinuations } \\
\hline TEAEs & $5(1.0)$ & $1(0.9)$ & $9(2.0)$ & $3(2.4)$ & $7(1.5)$ & $4(4.5)$ & $18(3.9)$ & $5(4.2)$ \\
\hline Drug-related TEAEs & $3(0.6)$ & $1(0.9)$ & $4(0.9)$ & $1(0.8)$ & $3(0.6)$ & $2(2.2)$ & $16(3.5)$ & $2(1.7)$ \\
\hline \multicolumn{9}{|c|}{ TEAEs ( $\geq 3 \%$ in any treatment group) } \\
\hline Dizziness & $24(5.0)$ & $5(4.4)$ & $47(10.3)$ & $11(8.9)$ & $14(3.0)$ & $3(3.4)$ & $48(10.5)$ & $9(7.6)$ \\
\hline Headache & $34(7.0)$ & $8(7.1)$ & $30(6.6)$ & $8(6.5)$ & $27(5.8)$ & $6(6.7)$ & $28(6.1)$ & $9(7.6)$ \\
\hline $\begin{array}{l}\text { Upper respiratory tract } \\
\text { infection }\end{array}$ & $19(3.9)$ & $7(6.2)$ & $16(3.5)$ & $2(1.6)$ & $12(2.6)$ & $2(2.2)$ & $13(2.9)$ & $3(2.5)$ \\
\hline Edema peripheral & $34(7.0)$ & $8(7.1)$ & $4(0.9)$ & $2(1.6)$ & $36(7.8)$ & $10(11.2)$ & $29(6.4)$ & $15(12.7)$ \\
\hline Fatigue & $30(6.2)$ & $4(3.5)$ & $25(5.5)$ & $6(4.9)$ & $29(6.3)$ & 7 (7.9) & $18(3.9)$ & $6(5.1)$ \\
\hline Nausea & $9(1.9)$ & $3(2.7)$ & $18(3.9)$ & $4(3.3)$ & $11(2.4)$ & $1(1.1)$ & $14(3.1)$ & $3(2.5)$ \\
\hline Hypokalemia & $1(0.2)$ & $1(0.9)$ & $3(0.7)$ & 0 & $23(5.0)$ & $2(2.2)$ & $3(0.7)$ & $1(0.8)$ \\
\hline Urinary tract infection & $7(1.4)$ & $1(0.9)$ & $5(1.1)$ & $1(0.8)$ & $6(1.3)$ & $1(1.1)$ & $7(1.5)$ & $7(5.9)$ \\
\hline Arthralgia & $8(1.7)$ & $4(3.5)$ & $9(2.0)$ & $2(1.6)$ & $9(1.9)$ & $3(3.4)$ & $8(1.8)$ & 0 \\
\hline Joint swelling & $11(2.3)$ & $6(5.3)$ & $1(0.2)$ & $1(0.8)$ & $12(2.6)$ & $4(4.5)$ & $3(0.7)$ & $9(7.6)$ \\
\hline Constipation & $4(0.8)$ & $2(1.8)$ & $3(0.7)$ & $3(2.4)$ & $12(2.6)$ & 0 & $5(1.1)$ & $5(4.2)$ \\
\hline Diarrhea & $9(1.9)$ & $5(4.4)$ & $10(2.2)$ & $2(1.6)$ & $8(1.7)$ & $1(1.1)$ & $10(2.2)$ & $5(4.2)$ \\
\hline Nasopharyngitis & $10(2.1)$ & $1(0.9)$ & $15(3.3)$ & $5(4.1)$ & $13(2.8)$ & $3(3.4)$ & $17(3.7)$ & $3(2.5)$ \\
\hline Muscle spasms & $8(1.7)$ & $4(3.5)$ & $11(2.4)$ & $3(2.4)$ & $11(2.4)$ & $2(2.2)$ & $17(3.7)$ & $1(0.8)$ \\
\hline Paraesthesia & $8(1.7)$ & $1(0.9)$ & $8(1.8)$ & 0 & $6(1.3)$ & $3(3.4)$ & $4(0.9)$ & 0 \\
\hline Dry mouth & $4(0.8)$ & $1(0.9)$ & $6(1.3)$ & $2(1.6)$ & $7(1.5)$ & $3(3.4)$ & $3(0.7)$ & $2(1.7)$ \\
\hline Blood glucose increased & $1(0.2)$ & $2(1.8)$ & 0 & $1(0.8)$ & $6(1.3)$ & $3(3.4)$ & $1(0.2)$ & 0 \\
\hline $\begin{array}{l}\text { Blood potassium } \\
\text { decreased }\end{array}$ & $1(0.2)$ & 0 & $3(0.7)$ & 0 & $10(2.2)$ & $4(4.5)$ & $5(1.1)$ & 0 \\
\hline Rash & $4(0.8)$ & $4(3.5)$ & $4(0.9)$ & $1(0.8)$ & $6(1.3)$ & $2(2.2)$ & $3(0.7)$ & $2(1.7)$ \\
\hline \multicolumn{9}{|l|}{ Other TEAEs } \\
\hline Cough & $7(1.4)$ & 0 & $12(2.6)$ & $3(2.4)$ & $9(1.9)$ & $2(2.2)$ & $8(1.8)$ & $3(2.5)$ \\
\hline Hypotension & 0 & 0 & $2(0.4)$ & $1(0.8)$ & 0 & 0 & $6(1.3)$ & $2(1.7)$ \\
\hline Orthostatic hypotension & 0 & 0 & $1(0.2)$ & 0 & 0 & 0 & $2(0.4)$ & 0 \\
\hline Vertigo & $2(0.4)$ & 0 & $1(0.2)$ & 0 & 0 & $1(1.1)$ & $2(0.4)$ & $1(0.8)$ \\
\hline Fall & $1(0.2)$ & 0 & $2(0.4)$ & $1(0.8)$ & $2(0.4)$ & $1(1.1)$ & $1(0.2)$ & $1(0.8)$ \\
\hline
\end{tabular}

${ }^{a}$ Due to the disproportionate sizes of the age groups and because the $\geq 75$ years of age group is included in the $\geq 65$ years of age group, only TEAEs $\geq 3 \%$ for the $<65$ years of age and $\geq 65$ years of age groups are shown

b TEAEs were adverse events that emerged during treatment, having been absent pre-treatment or worsened relative to the pre-treatment state. TEAEs are defined as having a start date on or after the first dose of double-blind medication

${ }^{c}$ Drug-related was defined as definitely, probably, or possibly related to randomized study medication

$\mathrm{AML}=$ amlodipine besylate; $\mathrm{HCTZ}=$ hydrochlorothiazide; $\mathrm{NR}=$ not reported; $\mathrm{OM}=$ olmesartan medoxomil; TEAE $=$ treatment-emergent adverse event

subgroups. Triple-combination treatment was well tolerated, with low prevalences of hypotension and few discontinuations due to drug-related TEAEs in both the $<65$ and $\geq 65$ years of age subgroups. Triple-combination treatment with OM 40/AML 10/HCTZ 25 mg may provide a safe and effective treatment option for elderly patients whose BP is not adequately controlled with dual-combination treatment. Other combinations of similar classes of medications may be efficacious at reducing BP, but will need to be evaluated. 
Acknowledgments Research funds for this study were provided by Daiichi Sankyo, Inc, Parsippany, New Jersey. The trial was designed by Daiichi Sankyo in conjunction with the investigators. Editorial support to the authors for this article was provided by Vrinda Mahajan, PharmD, of Peloton Advantage, LLC, Parsippany, New Jersey and was funded by Daiichi Sankyo, Inc. The opinions expressed in the current article are those of the authors. The authors received no honoraria/fee for service or other form of financial support related to the development of this article. Andrew J. Lewin, MD, has received Grants from 7TM Pharma, Abbott Laboratories, ActivX Biosciences Inc, Akros Pharma Inc, Amarin Pharma Inc, AstraZeneca, Boehringer Ingelheim Pharmaceuticals, Daiichi Sankyo Inc, Eli Lilly \& Company, Elixir Pharmaceuticals Inc, Essentials Inc, Forest Research Institute, GlaxoSmithKline, Hollis-Eden Pharmaceuticals, F. Hoffman-La Roche, Incyte Corporation, InteKrin Therapeutics Inc, Johnson \& Johnson, Kowa Research Institute, Merck \& Co. Inc, Metabasis, Metabolic Solutions Development Co., Novartis Pharmaceuticals Corp., Novo Nordisk, Pfizer Inc, Pharmacopeia Inc, Phenomix Corporation, Regeneron Pharmaceuticals, sanofi-aventis, sanofi pasteur, Schering-Plough, Surface Logix, Takeda Pharmaceuticals America, TAP Holdings Inc, Transition Therapeutics, Tularik Inc, VIVUS Inc, and Wyeth-Ayerst. Joseph L. Izzo, Jr., MD, has served as a consultant or investigator for Daiichi Sankyo Inc, Boehringer-Ingelheim, Novartis, GlaxoSmithKline, Takeda Pharmaceuticals, and Forest Laboratories. Michael Melino, PhD, James Lee, PhD, and Victor Fernandez, BS are employees of Daiichi Sankyo Inc. Reinilde Heyrman, MD is a former employee of Daiichi Sankyo, Inc.

Open Access This article is distributed under the terms of the Creative Commons Attribution Noncommercial License which permits any noncommercial use, distribution, and reproduction in any medium, provided the original author(s) and the source are credited.

\section{References}

1. Go AS, Mozaffarian D, Roger VL, et al. Heart disease and stroke statistics-2013 update-a report from the American Heart Association. Circulation. 2013;127(1):143-52.

2. Chobanian AV, Bakris GL, Black HR, et al. Seventh report of the Joint National Committee on Prevention, Detection, Evaluation, and Treatment of High Blood Pressure. Hypertension. 2003;42 (6):1206-52.

3. Yoon SS, Ostchega Y, Louis T. Recent trends in the prevalence of high blood pressure and its treatment and control, 1999-2008 [NCHS data brief, no. 48]. National Center for Health Statistics. http://www.cdc.gov/nchs/data/databriefs/db48.pdf. Accessed 25 April 2011.

4. Aronow WS, Fleg JL, Pepine CJ, et al. ACCF/AHA 2011 expert consensus document on hypertension in the elderly: a report of the American College of Cardiology Foundation Task Force on Clinical Expert Consensus documents. J Am Coll Cardiol. 2011;57(20):2037-114.

5. Kearney PM, Whelton M, Reynolds K, et al. Global burden of hypertension: analysis of worldwide data. Lancet. 2005;365 (9455):217-23.

6. Lewington S, Clarke R, Qizilbash N, et al. Age-specific relevance of usual blood pressure to vascular mortality: a meta-analysis of individual data for one million adults in 61 prospective studies. Lancet. 2002;360(9349):1903-13.

7. Lithell H, Hansson L, Skoog I, et al. The Study on Cognition and Prognosis in the Elderly (SCOPE): principal results of a randomized double-blind intervention trial. J Hypertens. 2003;21 (5):875-86.
8. Chapman RH, Benner JS, Petrilla AA, et al. Predictors of adherence with antihypertensive and lipid-lowering therapy. Arch Intern Med. 2005;165(10):1147-52.

9. Fung V, Huang J, Brand R, et al. Hypertension treatment in a medicare population: adherence and systolic blood pressure control. Clin Ther. 2007;29(5):972-84.

10. Boyle JP, Thompson TJ, Gregg EW, et al. Projection of the year 2050 burden of diabetes in the US adult population: dynamic modeling of incidence, mortality, and prediabetes prevalence. Popul Health Metr. 2010;8(1):29.

11. Calhoun DA. Use of single-pill combination therapy in the evolving paradigm of hypertension management. Expert Opin Pharmacother. 2009;10(12):1869-74.

12. Oparil S, Melino M, Lee J, et al. Triple therapy with olmesartan medoxomil, amlodipine besylate, and hydrochlorothiazide in adult patients with hypertension: the TRINITY multicenter, randomized, double-blind, 12-week, parallel-group study. Clin Ther. 2010;32(7):1252-69.

13. Amery A, Birkenhager W, Brixko P, et al. Mortality and morbidity results from the European Working Party on High Blood Pressure in the Elderly trial. Lancet. 1985;1(8442):1349-54.

14. SHEP Cooperative Research Group. Prevention of stroke by antihypertensive drug treatment in older persons with isolated systolic hypertension. Final results of the Systolic Hypertension in the Elderly Program (SHEP). JAMA. 1991;265(24):3255-64.

15. Dahlof B, Lindholm LH, Hansson L, et al. Morbidity and mortality in the Swedish Trial in Old Patients with Hypertension (STOP-Hypertension). Lancet. 1991;338(8778):1281-5.

16. Staessen J. Mortality and treated blood pressure in patients of the European Working Party on High Blood Pressure in the Elderly. Am J Med. 1991;90(3A):60S-61S.

17. MRC Working Party. Medical Research Council trial of treatment of hypertension in older adults: principal results. BMJ. 1992;304(6824):405-12.

18. Staessen JA, Fagard R, Thijs L, et al. Randomised double-blind comparison of placebo and active treatment for older patients with isolated systolic hypertension. The Systolic Hypertension in Europe (Syst-Eur) Trial Investigators. Lancet. 1997;350(9080): 757-64.

19. Liu L, Wang JG, Gong L, et al. Comparison of active treatment and placebo in older Chinese patients with isolated systolic hypertension. Systolic Hypertension in China (Syst-China) Collaborative Group. J Hypertens. 1998;16(12 Pt 1):1823-9.

20. Beckett NS, Peters R, Fletcher AE, et al. Treatment of hypertension in patients 80 years of age or older. $\mathrm{N}$ Engl J Med. 2008;358(18):1887-98.

21. Musini VM, Tejani AM, Bassett K, et al. Pharmacotherapy for hypertension in the elderly. Cochrane Database Syst Rev. 2009; (4):CD000028.

22. Schall P, Wehling M. Treatment of arterial hypertension in the very elderly: a meta-analysis of clinical trials. Arzneimittelforschung. 2011;61(4):221-8.

23. Malacco E, Omboni S, Volpe M, et al. Antihypertensive efficacy and safety of olmesartan medoxomil and ramipril in elderly patients with mild to moderate essential hypertension: the ESPORT study. J Hypertens. 2010;8(11):2342-50.

24. Omboni S, Malacco E, Mallion JM, et al. Twenty-four hour and early morning blood pressure control of olmesartan vs. ramipril in elderly hypertensive patients: pooled individual data analysis of two randomized, double-blind, parallel-group studies. J Hypertens. 2012;30(7):1468-77.

25. Gradman AH, Basile JN, Carter BL, et al. Combination therapy in hypertension. J Am Soc Hypertens. 2010;4(1):42-50.

26. Cushman WC, Ford CE, Cutler JA, et al. Success and predictors of blood pressure control in diverse North American settings: the antihypertensive and lipid-lowering treatment to prevent heart 
attack trial (ALLHAT). J Clin Hypertens (Greenwich). 2002;4(6): 393-404.

27. Black HR, Elliott WJ, Grandits G, et al. Principal results of the Controlled Onset Verapamil Investigation of Cardiovascular End Points (CONVINCE) trial. JAMA. 2003;289(16):2073-82.

28. Jamerson K, Weber MA, Bakris GL, et al. Benazepril plus amlodipine or hydrochlorothiazide for hypertension in high-risk patients. N Engl J Med. 2008;359(23):2417-28.

29. Gradman AH. Rationale for triple-combination therapy for management of high blood pressure. J Clin Hypertens (Greenwich). 2010;12(11):869-78.

30. Dahlof B, Sever PS, Poulter NR, et al. Prevention of cardiovascular events with an antihypertensive regimen of amlodipine adding perindopril as required versus atenolol adding bendroflumethiazide as required, in the Anglo-Scandinavian Cardiac Outcomes Trial-Blood Pressure Lowering Arm (ASCOT-BPLA): a multicentre randomised controlled trial. Lancet. 2005;366(9489): 895-906.

31. Chapman N, Chang CL, Dahlof B, et al. Effect of doxazosin gastrointestinal therapeutic system as third-line antihypertensive therapy on blood pressure and lipids in the Anglo-Scandinavian Cardiac Outcomes Trial. Circulation. 2008;118(1):42-8.

32. Kereiakes DJ, Neutel J, Stoakes KA, et al. The effects of an olmesartan medoxomil-based treatment algorithm on 24-hour blood pressure levels in elderly patients aged 65 and older. J Clin Hypertens (Greenwich). 2009;11(8):411-21.

33. Oparil S, Pimenta E. Efficacy of an olmesartan medoxomil-based treatment algorithm in patients stratified by age, race, or sex. J Clin Hypertens (Greenwich). 2010;12(1):3-13.

34. Oparil S, Chrysant SG, Melino M, et al. Long-term efficacy of a combination of amlodipine and olmesartan medoxomil $t$ hydrochlorothiazide in patients with hypertension stratified by age, race and diabetes status: a substudy of the $\mathrm{COACH}$ trial. J Hum Hypertens. 2010;24(12):831-8.

35. Neutel J, Kereiakes DJ, Stoakes KA, et al. Blood pressure-lowering efficacy of an olmesartan medoxomil/hydrochlorothiazidebased treatment algorithm in elderly patients (age $\geq 65$ years) stratified by age, sex and race: subgroup analysis of a 12-week, open-label, single-arm, dose-titration study. Drugs Aging. 2011;28(6):477-90.

36. Schmieder RE, Bohm M. Efficacy and safety of olmesartan medoxomil plus amlodipine in age, gender and hypertension severity defined subgroups of hypertensive patients. J Hum Hypertens. 2011;25(6):354-63.

37. Kereiakes DJ, Chrysant SG, Izzo JL Jr, et al. Olmesartan/amlodipine/hydrochlorothiazide in participants with hypertension and diabetes, chronic kidney disease, or chronic cardiovascular disease: a subanalysis of the multicenter, randomized, doubleblind, parallel-group TRINITY study. Cardiovasc Diabetol. 2012; 11(1):134.

38. Volpe M, Christian RL, Ammentorp B, et al. Efficacy and safety of triple antihypertensive therapy with the olmesartan/amlodipine/hydrochlorothiazide combination. Clin Drug Investig. 2012;32(10):649-64.

39. Jackson KC, Sheng X, Nelson RE, et al. Adherence with multiple-combination antihypertensive pharmacotherapies in a US managed care database. Clin Ther. 2008;30(8):1558-63.

40. Yiannakopoulou EC, Papadopulos JS, Cokkinos DV, et al. Adherence to antihypertensive treatment: a critical factor for blood pressure control. Eur J Cardiovasc Prev Rehabil. 2005;12 (3):243-9.

41. Veronesi M, Cicero AF, Prandin MG, et al. A prospective evaluation of persistence on antihypertensive treatment with different antihypertensive drugs in clinical practice. Vasc Health Risk Manag. 2007;3(6):999-1005.

42. Ho PM, Magid DJ, Shetterly SM, et al. Importance of therapy intensification and medication nonadherence for blood pressure control in patients with coronary disease. Arch Intern Med. 2008; 168(3):271-6.

43. Black HR. Triple fixed-dose combination therapy. Back to the past. Hypertension. 2009;54(1):19-22.

44. Bangalore S, Kamalakkannan G, Parkar S, et al. Fixed-dose combinations improve medication compliance: a meta-analysis. Am J Med. 2007;120(8):713-9.

45. Brixner DI, Jackson KC, Sheng X, et al. Assessment of adherence, persistence, and costs among valsartan and hydrochlorothiazide retrospective cohorts in free- and fixed-dose combinations. Curr Med Res Opin. 2008;24(9):2597-607.

46. Hess G, Hill J, Lau H, et al. Medication utilization patterns and hypertension-related expenditures among patients who were switched from fixed-dose to free-combination antihypertensive therapy. P T. 2008;33(11):652-66.

47. Gupta AK, Arshad S, Poulter NR. Compliance, safety, and effectiveness of fixed-dose combinations of antihypertensive agents: a meta-analysis. Hypertension. 2010;55(2):399-407.

48. Yang W, Chang J, Kahler KH, et al. Evaluation of compliance and health care utilization in patients treated with single pill vs. free combination antihypertensives. Curr Med Res Opin. 2010; 26(9):2065-76.

49. Zeng F, Patel BV, Andrews L, et al. Adherence and persistence of single-pill ARB/CCB combination therapy compared to multiplepill ARB/CCB regimens. Curr Med Res Opin. 2010;26(12): 2877-87. 